\title{
Acute myocardial infarction caused by intravenous amphetamine abuse
}

\author{
G E Packe, M J Garton, K Jennings
}

\begin{abstract}
A man aged 27 years presented with an acute myocardial infarction after injecting himself intravenously with amphetamine. Soon after admission ventricular fibrillation developed. This was successfully cardioverted. Coronary arteriography was normal.
\end{abstract}

Myocardial infarction is a rarely reported complication of amphetamine abuse. We describe a patient in whom an acute myocardial infarction developed after intravenous injection of amphetamine.

\section{Case report}

A 27 year old man injected himself intravenously with two doses (total $1.5 \mathrm{~g}$ ) of amphetamine at an interval of half an hour. An hour later he felt unwell and after four hours severe central chest pain developed. He had previously taken amphetamine without symptoms and had misused other drugs such as heroin and cannabis. He smoked 15 cigarettes per day and drank alcohol occasionally. His father had a history of ischaemic heart disease.

Two and a half hours after the onset of chest pain he was admitted to hospital. The electrocardiogram showed evidence of an anterolateral myocardial infarction (figure). The chest radiograph was normal. He was treated with intravenous diamorphine $5 \mathrm{mg}$ and prochlorperazine $12.5 \mathrm{mg}$. Soon afterwards he had a cardiac arrest and the cardiac monitor showed ventricular fibrillation. $\mathrm{He}$ was successfully cardioverted by a single direct current shock of $400 \mathrm{~J}$. He was subsequently given 1.5 megaunits of streptokinase. Over the ensuing 24 hours the electrocardiographic monitor showed frequent ventricular extrasystoles, several self-terminating runs of ventricular tachycardia, and intermittently a nodal rhythm. Thereafter he made an uncomplicated recovery. Blood taken after he was resuscitated showed a rise in serum alanine aminotransferase reaching a maximum of $224 \mathrm{U} / 1$ the day after admission, and in lactate dehydrogenase reaching a maximum of $556 \mathrm{U} / 1$ two days after admission. Gamma glutamyl transferase rose to 104 $\mathrm{U} / \mathrm{l}$ two days after admission. Antibodies to hepatitis B antigen and human immunodeficiency virus were not detected in his serum. Before discharge from hospital he was able to complete a limited treadmill exercise test without symptoms developing: inverted $\mathrm{T}$ waves, which were evident on the electrocardiogram before exercise, became upright during exercise. He was discharged after one week and advised to take aspirin $150 \mathrm{mg}$ daily. He was strongly urged to avoid drug misuse in the future.

After two months he was readmitted for additional investigations. His electrocardiogram had by now reverted to normal. Fasting blood lipids were normal. He performed a
Regional Cardiac Centre, Aberdeen Royal Infirmary, Aberdeen G E Packe M J Garton K Jennings

Correspondence to Dr G E Packe, Chest Clinic, City Hospital, Urquhart Street, Aberdeen AB9 8AU.
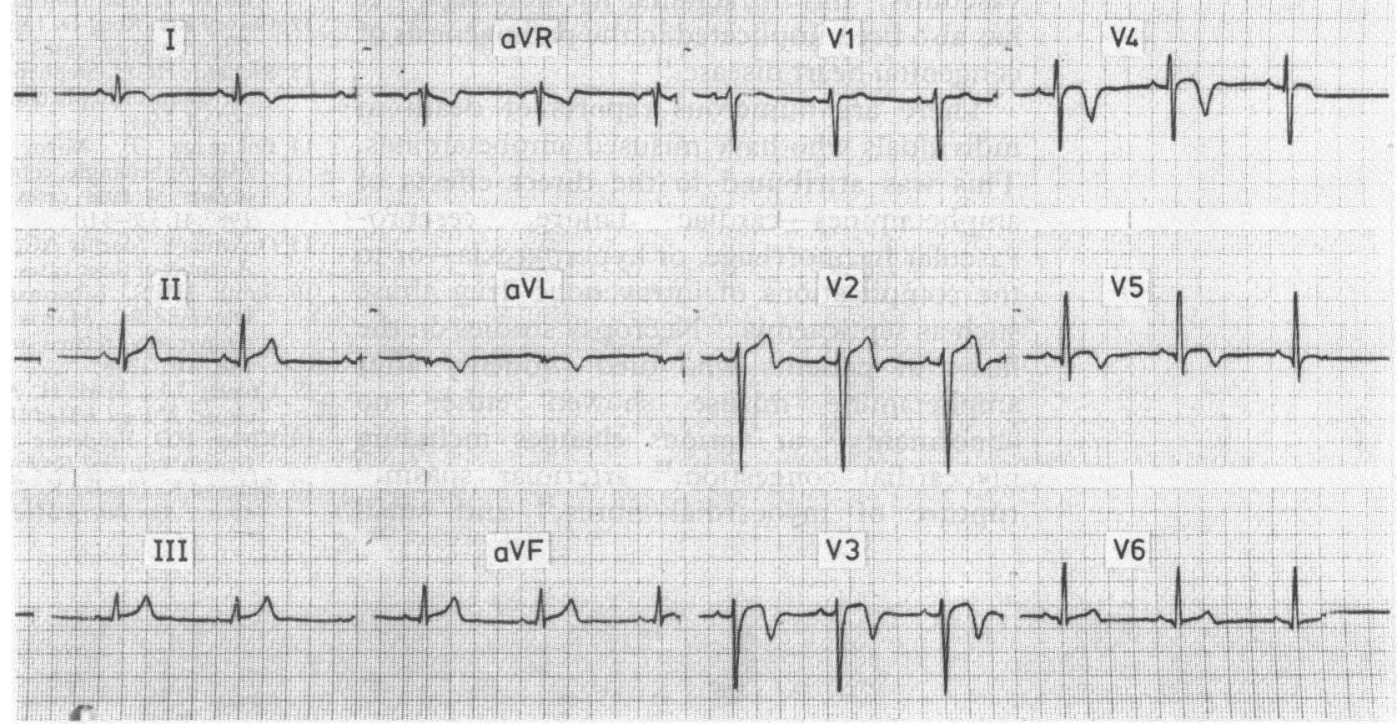

Figure Electrocardiogram on admission to hospital. 
repeat exercise test using the full Bruce protocol and was able to accomplish $12 \mathrm{~min}$ utes without symptoms developing; the electrocardiogram remained normal throughout the test. Coronary arteriography was normal but the ventriculogram showed a small area of apical dyskinesia.

\section{Discussion}

Our patient sustained an acute myocardial infarction after intravenous injection of amphetamine. There have been only two previous reports showing a clear relation between amphetamine misuse and myocardial infarction. Carson et al described a patient aged 33 years in whom chest pain developed one hour after intravenous injection of amphetamine. ${ }^{1}$ His electrocardiogram showed an inferolateral myocardial infarction; coronary arteriography was normal. In the patient described by Marsden and Sheldon an anterior myocardial infarction developed after he had ingested the contents of a propylhexedrine aerosol inhaler; adult respiratory distress syndrome also developed. ${ }^{2}$ Four of six patients reported by Anderson and Scott experienced chest pain after receiving amphetamine. ${ }^{3}$ In one heart block also developed but the electrocardiographic findings in the other patients were not described.

Myocardial infarction after amphetamine abuse may have been caused by coronary artery spasm. Amphetamine stimulates release of noradrenaline from sympathetic nerves; this has a pressor effect on the coronary circulation. ${ }^{4}$ Alternatively, transient occlusion of the coronary vessels may have been caused by platelet thrombi: catecholamines are known to induce platelet aggregation. ${ }^{5}$ These effects may have been aggravated by an increase in myocardial oxygen demand induced by catecholamines. ${ }^{4}$

In addition to myocardial infarction, amphetamine abuse has been implicated in the aetiology of other cardiovascular disorders including acute $^{6}$ and chronic cardiomyopathy, ${ }^{7}$ cor pulmonale, ${ }^{8}$ necrotising vasculitis, ${ }^{9}$ and intracranial haemorrhage. ${ }^{10}$ It has also been implicated in the pathogenesis of congenital heart disease. ${ }^{11}$

There are numerous reports of death in individuals who have misused amphetamines. This was attributed to the direct effects of amphetamines-cardiac failure, cerebrovascular haemorrhage, or hyperpyrexia-or to the complications of intravenous drug abuse such as septicaemia. ${ }^{10}$ Necropsy studies on the heart in patients who died suddenly after amphetamine misuse showed either no abnormality $^{10}$ or various changes including myocardial congestion, ${ }^{12}$ arteriolar spasm, ${ }^{13}$ rupture of myocardial fibres, ${ }^{14}$ and small interstitial $^{14}$ and endocardial haemorrhages ${ }^{15}$; there are no reports of myocardial infarction. Although amphetamine abuse has the potential to cause myocardial infarction, it is likely that in many cases ventricular fibrillation supervenes before the changes of myocardial infarction become manifest.

Cocaine abuse has been strongly associated with myocardial infarction. ${ }^{16}$ Like amphetamine, it enhances noradrenaline release and probably causes myocardial ischaemia by inducing coronary artery vasospasm and by increasing myocardial oxygen demand. ${ }^{1617}$ Recreational use of the purer, free-base form of cocaine (crack) has reached epidemic proportions in North America and there are fears that use of crack could become widespread in the United Kingdom. ${ }^{18}$ Cocaine is often diluted (cut) with other agents such as amphetamine before it is sold, so drug misusers are often unaware of the exact composition of the drugs they are taking. ${ }^{19}$ This raises the possibility that the patient we describe may inadvertently have taken a combination of amphetamine and cocaine which may have had an additive effect in provoking myocardial ischaemia.

1 Carson P, Oldroyd K, Phadke K. Myocardial infarction due to amphetamine. Br Med J 1987;294:1525-6.

2 Marsden P, Sheldon I. Acute poisoning by propylhexedrine. Br Med J 1972;i:730.

3 Anderson EW, Scott WC. Cardiovascular effects of benzedrine. Lancet 1936;ii:1461-2.

4 Feigl EO. Coronary physiology. Physiol Rev 1983;63:1-205.

5 Haft JI, Kranz PD, Albert FJ, Fanoi K. Intravascular platelet aggregation in the heart induced by norepineplatelet aggregation in the heart induced by norepine-

6 Call TD, Hartneck J, Dickinson WA, Hartman CW, Bartel AG. Acute cardiomyopathy secondary to intravenous AG. Acute cardiomyopathy secondary to intravenou

Croft CH, Firth BG, Hillis LD. Propylhexedrine-induced left ventricular dysfunction. Ann Intern Med 1982; 97:560-1

8 Anderson RJ, Garza HR, Garriot JC, Dimaio V. Intravenous propylhexedrine (Benzedrex) abuse and sudden death Am J Med 1979;67:15-20.

9 Citron BP, Halpern M, McCarron M. Necrotizing angiitis associated with drug abuse. $N$ Engl J Med 1970;283: 1003-11.

10 Kalant H, Kalant OJ. Death in amphetamine users: causes and rates. Can Med Assoc J 1975;112:299-304.

11 Nora JJ, Vargo TA, Nora AH, Love KE, McNamara DG. Dexamphetamine: a possible environmental trigger in cardiovascular malformations. Lancet 1970;i:1290-1.

12 Cravey RH, Reed D. Intravenous amphetamine poisoning. Report of three cases. J Forensic Sci Soc 1970;10:109-12.

13 Richards HGH, Stephens A. Sudden death associated with the taking of amphetamines by an asthmatic. Med Sci Law the taking of am

14 Fukunaga T, Mizoi Y, Adachi J, Tatsuno Y. Metamphetamine concentrations in blood, urine, and organs of fatal cases after abuse. Jpn J Legal Med 1987;41:328-34

15 Orrenius S, Maehly AC. Lethal amphetamine intoxication. A report of three cases. $J$ Legal Med 1970;67:184-9.

16 Smith HWB, Liberman HA, Brody SL, Battey LL, Donohue BC, Morris DC. Acute myocardial infarction temporarily related to cocaine use. Ann Intern Med 1987;107:13-8.

17 Cregler LL, Mark H. Medical complications of cocaine abuse. N Engl J Med 1986;315:1495-500.

18 Kleber HD. Epidemic cocaine abuse: America's present, Britain's future? $B r J$ Addict 1988;83:1359-71.

19 Oldroyd K, Phadke K, Carson P. Complications of cocaine abuse. Ann Intern Med 1987;107:940. 